\title{
IMAGES IN MEDICAL PRACTICE
}

\section{A Young Male Presenting with Polyuria and Unilateral Exophthalmos}

\author{
A Das ${ }^{\mathrm{a}}$, FA Cader ${ }^{\mathrm{b}}$
}

(J Banagladesh Coll Phys Surg 2014; 32: 241-243)

A 16-year-old boy from Nilphamari, Bangladesh presented with the complaints of gradual swelling of the left eye with protrusion over 1 year, increased thirst with polyuria for 2 months, and weight loss of around 5 $\mathrm{kg}$ over the same duration. The eye swelling was insidious in onset, limited to the left eye, associated with some redness but no lacrimation or fever and headache. He complained of excessive thirst, having to take up to 16 litres of water per day, which was associated with polyuria, including nocturia. He also developed two bony swellings on the left side of his skull which was associated with mild tenderness on palpation. He gave no history of bony pain, breathlessness, polyphagia or features of hyperthyroidism. On examination, there was non-tender proptosis of the left eye, but devoid of lid

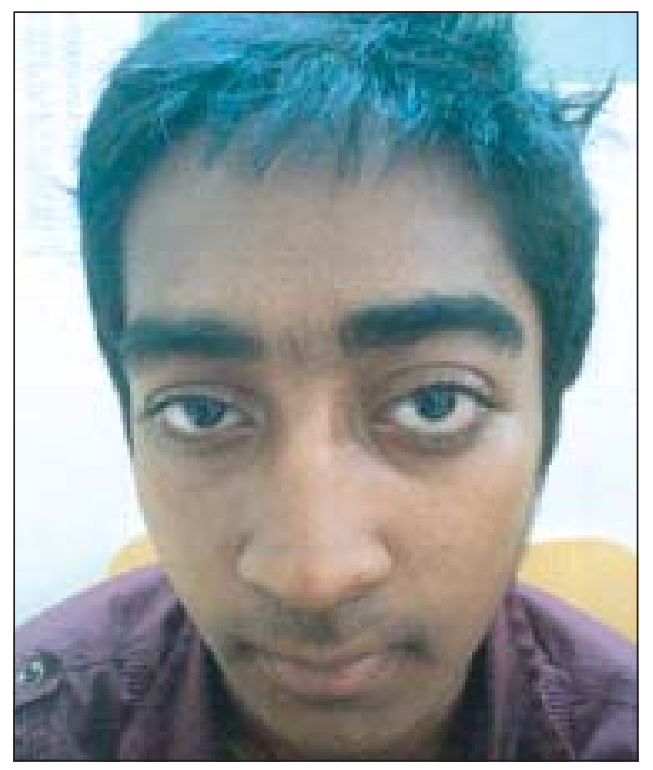

retraction, lidlag or ophthalmoplegia (Fig-1). All cranial nerves examination including funduscopy revealed no abnormality. He was haemodynamically stable and not dehydrated.

Investigations revealed normal haemogram, urea, creatinine and electrolytes, and normal blood glucose levels, effectively ruling out diabetes mellitus. ESR 70mm/ $1^{\text {st }}$ hour. Thyroid profile was normal. Xray skull showed lytic lesions in frontal and parietal bones (Fig- 2)

CT scan of orbit showed a minimal enhancing soft tissue density mass lesion measuring $2 \times 1 \mathrm{~cm}$ in left orbit with minimal surrounding bony erosion suggestive of Histiocytosis X (Fig- 3) . MRI of the brain was unremarkable.

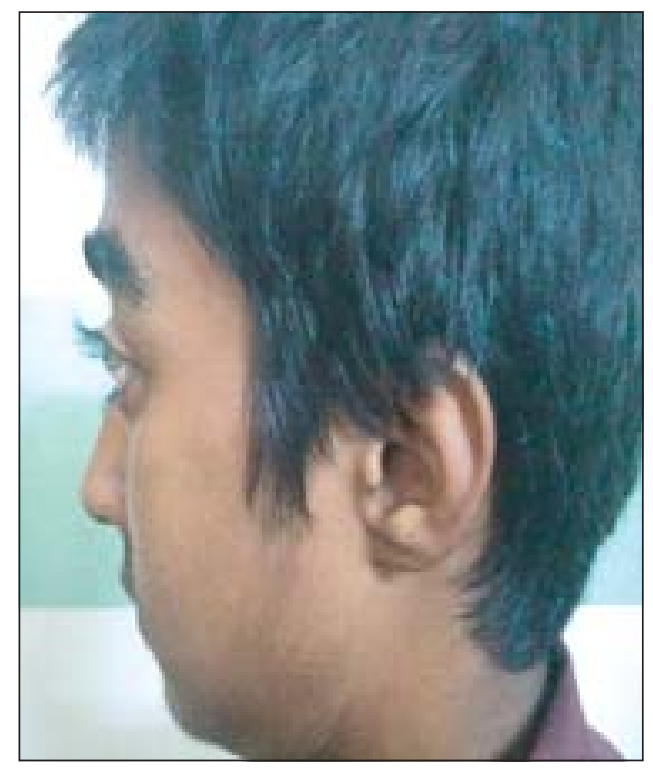

Fig-1: Photograph showing Left sided exophthalmos front view and profile view.

a. Dr. Aparna Das, Associate Professor, Department of Medicine, Dhaka Medical College Hospital, Dhaka

b. $\quad$ Dr. F. Aaysha Cader, Honorary Medical Officer, Department of Medicine, Dhaka Medical College Hospital, Dhaka.

Address of Correspondence: Dr. Aparna Das, Associate Professor, Department of Medicine, Dhaka Medical College Hospital, Dhaka. Email : aparna_0191@yahoo.com 

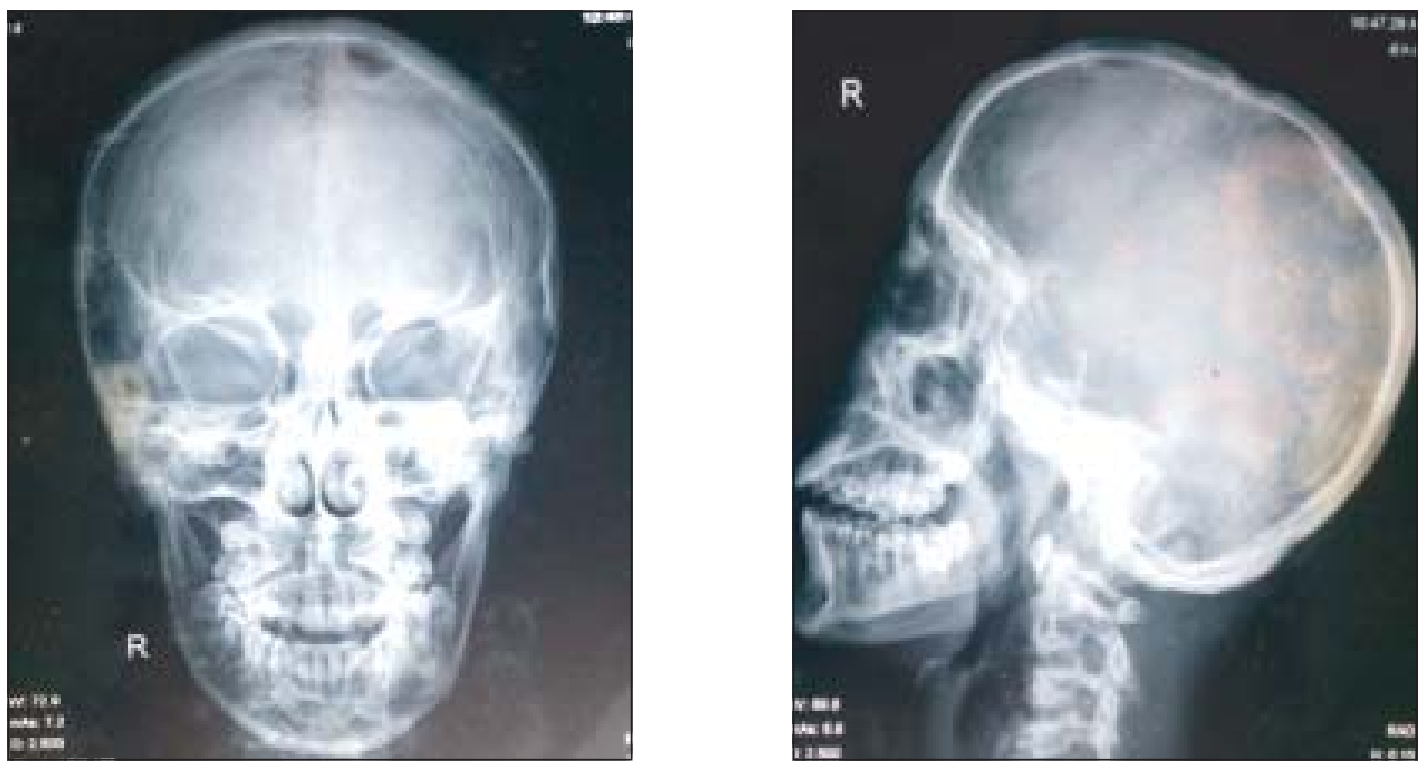

Fi-2: $X$ ray skull showing lytic skull lesions of frontal and parietal bones.
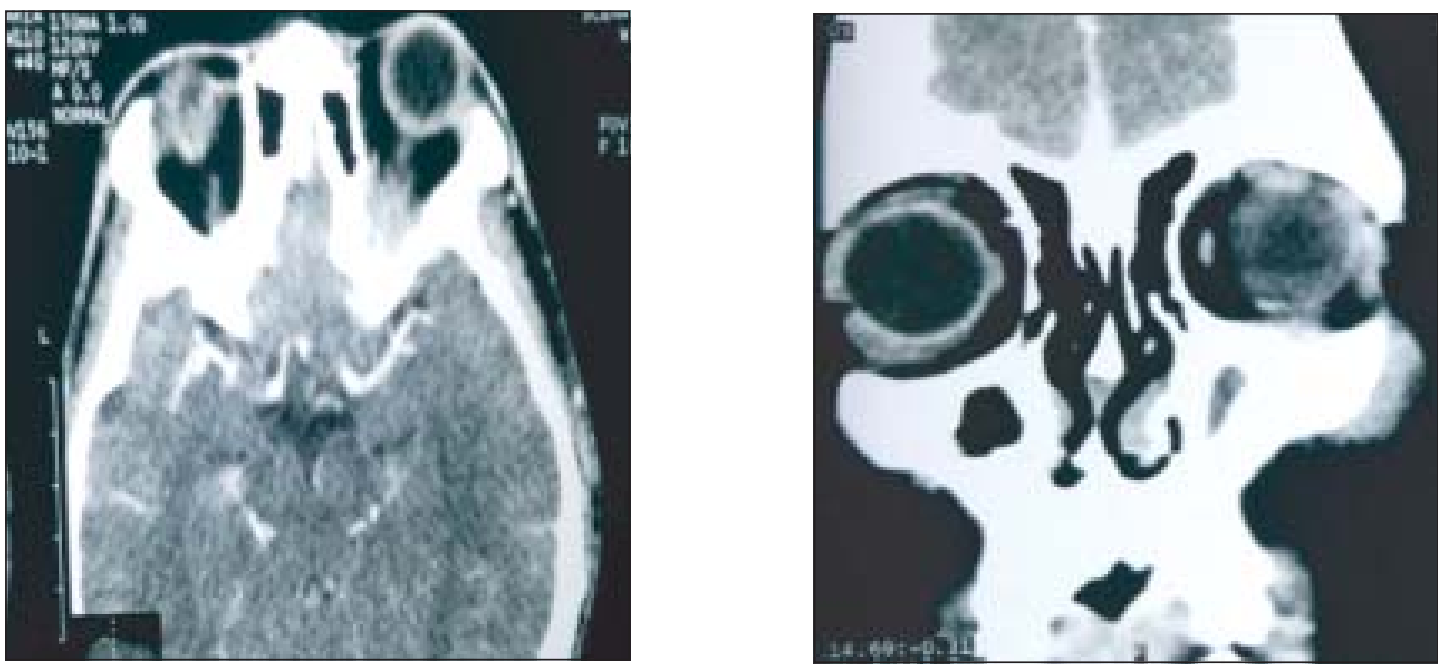

Fig-3: CT scan of the orbit showing soft tissue mass in left orbit.

Urine osmolality: 32mosm $/ \mathrm{kg}$. Serum osmolality: $285 \mathrm{mosm} / \mathrm{kg}$. Subsequent water deprivation test revealed the following : dehydration phase commenced at 7.30am. 2 hours later, urine osmolality: $84 \mathrm{mosm} / \mathrm{kg}$; 4 hours later, urine osmolality: $140 \mathrm{mosm} / \mathrm{kg}$; test was terminated at 5 hours as patient developed intolerablethirst and $1.5 \mathrm{~kg}$ weight loss. At the end of the test urine osmolality had increased to $184 \mathrm{mosm} / \mathrm{kg}$; serum osmolality: 275mosm $/ \mathrm{kg}$. 2 puffs of DDAVP was given and serum osmolality measured $1 \mathrm{hr} 30$ minutes later had increased to $346 \mathrm{mosm} / \mathrm{kg}$, suggestive of Central Diabetes Insipidus (CDI).

Bone marrow biopsy revealed features suggestive of reactive normal marrow. Skin biopsy showed dermis revealing perivascular infiltrate of chronic inflammatory cells. Bone biopsy was suggestive of histiocytosis X.

He was commenced on 2 puffs DDAVP spray in each nostril at night, which resulted in a significant reduction of water intake as well as urine output which reduced to 
4-5L/day. At 3 month follow up, the patient was well on same dose, with improved constitutional symptoms and no nocturia, as well as reduced exophthalmos due to spontaneous regression of the orbital lesion.

\section{Discussion:}

Hand Schüller Christian (HSC) disease is one of the three components included in Langerhans cell histiocytosis, the other two being eosinophilic granuloma and Letterer-Siwe disease. The classical triad of HSC disease - exophthalmos, diabetes insipidus, and calvarial lytic lesions - is seen only in one-third of patients. ${ }^{1,2}$ Also known as Multifocal HistiocytosisX syndrome, HSC is the chronic form of disseminated Histiocytosis $\mathrm{X}$ in which the skeletal system and soft tisues may be involved.It usually affects young children,more commonly seen in boys, with male:female ratio of approximately $2: 1 .^{2}$

The most common site for solitary bone lesion is skull followed by long bones extremities, pelvis, ribs, scapula and spine. They are characterized in radiographs by single or multiple, round or oval lytic defects involving the medullary cavity. 2,3

Central diabetes insipidus (CDI) is associated in 15$25 \%$ cases of Histiocytosis X, about half of whom manifest CDI early in the disease. ${ }^{3,4}$ CDI may be associated with pituitary stalk thickening on imaging, although not present in all cases.75\% of cases with CDI go on to disease free survival but require hormonal replacement. $^{3}$
Unilateral or bilateral ocular and peri-orbital involvement resulting in exophthalmos, as well as scalp disease has also been reported. ${ }^{4}$

LCH is usually a self-limiting disease. In the absence of organ dysfunction, patients with either localized or multifocal LCH have an excellent prognosis. ${ }^{5}$

Treatment of Histiocytosis $\mathrm{X}$ may involve chemotherapy, radiotherapy or curettage surgery of the skull lesions. However as our patient showed spontaneous regression of the orbital lesion at follow up, he was continued on DDAVP spray, and no further intervention, as studies have shown that spontaneously regressing lesions need not be resected. ${ }^{6}$

\section{References:}

1. Cugati G, Singh M, PAndeA, Ramamurthi R, Vasudevan MC. Hand Schuller Christian disease. Indian J Med PaediatrOncol. 2011; 32(3): 183-184.

2. Bhargava D, Bhargava K, Hazarey V, Ganvir SM. HandSchüller-Christian disease. Indian J Dent Res 2012; 23: 830832

3. Shah AK, Solanki RN, Mahajan A. Hand Schuller Christian disease causing diabetes insipidus. Indian J Radiol Imaging 2003; 13: 297-300.

4. Tebbi CK. Histiocytosis Clinical Presentation [online]. http:/ /emedicine.medscape.com/article/958026-clinical\#a0217 (Accessed on 27.09.2013)

5. Mayer J.S, Harty MP, Mahboubi S etal 1995 Langerhans cell histiocytosis; presentation and evaluation of radiological findings with clinical correlation. Radiographics 15: 1135-1146.

6. Davidson L, McComb JG, Bowen I, Krieger MD. Craniospinal Langerhans cell histiocytosis in children: 30 years' experience at a single institution. J Neurosurg Pediatr. 2008; 1(3): 187-195. 